\title{
Early, regular breast-milk pumping may lead to early breast-milk feeding cessation
}

\author{
Jennifer Yourkavitch ${ }^{1, *}$, Kathleen M Rasmussen ${ }^{2}$, Brian W Pence ${ }^{1}$, Allison Aiello ${ }^{1}$, \\ Susan Ennett ${ }^{3}$, Angela M Bengtson ${ }^{1}$, Ellen Chetwynd ${ }^{4}$ and Whitney Robinson ${ }^{1}$ \\ 'Department of Epidemiology, Gillings School of Global Public Health, University of North Carolina, Chapel Hill, NC \\ 27599-7435, USA: ${ }^{2}$ Division of Nutritional Sciences, Cornell University, lthaca, NY, USA: ${ }^{3}$ Department of Health \\ Behavior, Gillings School of Global Public Health, University of North Carolina, Chapel Hill, NC, USA: ${ }^{4}$ Department \\ of Food, Bioprocessing and Nutrition Science, North Carolina State University, Raleigh, NC, USA
}

Submitted 9 July 2017: Final revision received 7 December 2017: Accepted 13 December 2017: First published online 13 February 2018

\begin{abstract}
Objective: To estimate the effect of early, regular breast-milk pumping on time to breast-milk feeding (BMF) and exclusive BMF cessation, for working and nonworking women.

Design: Using the Infant Feeding Practices Survey II (IFPS II), we estimated weighted hazard ratios (HR) for the effect of regular pumping (participant defined) compared with non-regular/not pumping, reported at month 2 , on both time to BMF cessation (to 12 months) and time to exclusive BMF cessation (to 6 months), using inverse probability weights to control confounding.

Setting: USA, 2005-2007.

Subjects: BMF ( $n$ 1624) and exclusively BMF ( $n$ 971) IFPS II participants at month 2 .

Results: The weighted HR for time to BMF cessation was 1.62 (95\% CI 1.47, 1.78) and for time to exclusive BMF cessation was 1.14 (95\% CI 1.03, 1.25). Among nonworking women, the weighted HR for time to BMF cessation was 2.05 (95\% CI $1 \cdot 84,2 \cdot 28)$ and for time to exclusive BMF cessation was $1 \cdot 10$ (95\% CI 0.98, 1.22). Among working women, the weighted HR for time to BMF cessation was 0.90 (95\% CI $0.75,1.07)$ and for time to exclusive BMF cessation was 1.14 (95\% CI 0.96, $1 \cdot 36)$.

Conclusions: Overall, regular pumpers were more likely to stop BMF and exclusive BMF than non-regular/non-pumpers. Non-working regular pumpers were more likely than non-regular/non-pumpers to stop BMF. There was no effect among working women. Early, regular pumpers may need specialized support to maintain BMF.
\end{abstract}

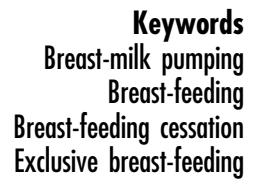

Breast-feeding has numerous benefits for maternal and child health $^{(1)}$ and society ${ }^{(2)}$. Exclusive breast-feeding is recommended for 6 months and continued breast-feeding for $1^{(3)}$ or 2 years or beyond ${ }^{(4)}$. However, as recently as 2013 , only $22 \%$ of infants born in the USA were exclusively breast-fed for 6 months and $31 \%$ were still breastfed at 12 months $^{(5)}$. In 2015, nearly $55 \%$ of all mothers with a child under 1 year of age were working in the USA $^{(6)}$. The timing of most women's return to work after birth overlaps with the recommended time frame for breast-feeding; nearly half of working mothers returned to work within 8 weeks of taking parental leave and $22 \%$ returned within 2 weeks ${ }^{(7)}$. Employed mothers have lower initiation rates and shorter durations of breast-feeding than those who are unemployed ${ }^{(2)}$.
One way for women to continue breast-milk feeding (BMF; including feeding at breast and feeding expressed breast milk) while working is to pump breast milk when separated from their infants ${ }^{(2)}$. The prevalence of breast-milk pumping is increasing ${ }^{(8)}$, but its effect on duration among mothers returning to work in the early postpartum period is unknown. Pumping may enable women to continue BMF longer than if they had not pumped ${ }^{(9,10)}$, and current policies encourage pumping as a way to extend BMF duration ${ }^{(11)}$, but there is mixed evidence for an association of pumping with BMF duration ${ }^{(8)}$. For example, in one observational study, low-income mothers who were given a breast pump requested formula 4 months after mothers who did not receive a pump ${ }^{(10)}$. In another observational study, however, mothers who pumped for non-elective reasons (including 
employment) had shorter BMF durations than those who pumped electively (e.g. to donate to another infant ${ }^{(12)}$.

The purpose of the present study was to estimate the effect of early (defined as infant age less than 9 weeks), regular breast-milk pumping (participant defined) on time to BMF and exclusive BMF cessation, for working and non-working women in the USA. Better understanding of the relationship between early, regular pumping and BMF durations is critical to ascertain if workplace policies that support breast pumping actually have the intended consequence of extending the duration of BMF.

\section{Methods}

The Infant Feeding Practices Survey II (IFPS II) was conducted by the US Centers for Disease Control and Prevention, the US Food and Drug Administration and other partners from 2005 to 2007 . Its methods are reported in detail elsewhere $^{(13)}$ and briefly summarized here.

\section{Study population and data collection}

The original study cohort comprised 3033 women who were aged 18 years or older in their third trimester and who delivered a live, singleton infant weighing $5 \mathrm{lb}$ ( 2268 g) or more at 35 weeks or more of gestation, spent $3 \mathrm{~d}$ or fewer in the neonatal intensive care unit and completed the neonatal survey ${ }^{(14)}$. Those women were members of, or living in the household of a member of, a consumer opinion panel. Using that panel was deemed the most efficient way to identify a nationally distributed group that was likely to complete multiple questionnaires $^{(13)}$. The women completed a prenatal questionnaire at the time of enrolment, reporting information pertaining to prenatal care, maternal diet and postnatal plans for infant care and feeding, and then a telephone survey to report birth-related data, after which investigators confirmed eligibility. Women completed subsequent questionnaires monthly during months 2 to 7 and then every 7 weeks until month 12, providing information about childcare, employment, infant feeding practices, sleep, maternal depression and infant health.

From the original study cohort ( $n$ 3033), we selected women who reported BMF on the month 2 questionnaire ( $n$ 1624), when the exposure (regular pumping) was measured (first analysis). For the second analysis, we selected women exclusively BMF at the time they completed the month 2 questionnaire ( $n$ 971) from the original study cohort (Fig. 1). Both BMF and exclusive BMF were determined by responses to questions about food consumed by the infant in the past $7 \mathrm{~d}$. If her infant consumed only breast milk, then a woman was considered to be exclusively $\mathrm{BMF}^{(14)}$.

\section{Exposure assessment}

The exposure for the present study is 'regular pumping' (including expressing breast milk in any way but not further defined on the questionnaire) that began when the infant was less than 9 weeks of age. Mothers responded to: 'Are you now pumping milk on a regular schedule?' (answer: yes or no), followed by 'How old was your baby when you first began pumping on a regular schedule?' (answer: number of days or weeks) on the 2-month questionnaire $^{(15)}$. 'Regular schedule' was not defined on the questionnaire. Less than $10 \%$ of questionnaires intended to be completed at month 2 ( 8.6 weeks) were completed at 13 weeks or more after birth. All mothers who were not regularly pumping or not pumping at all were considered unexposed.

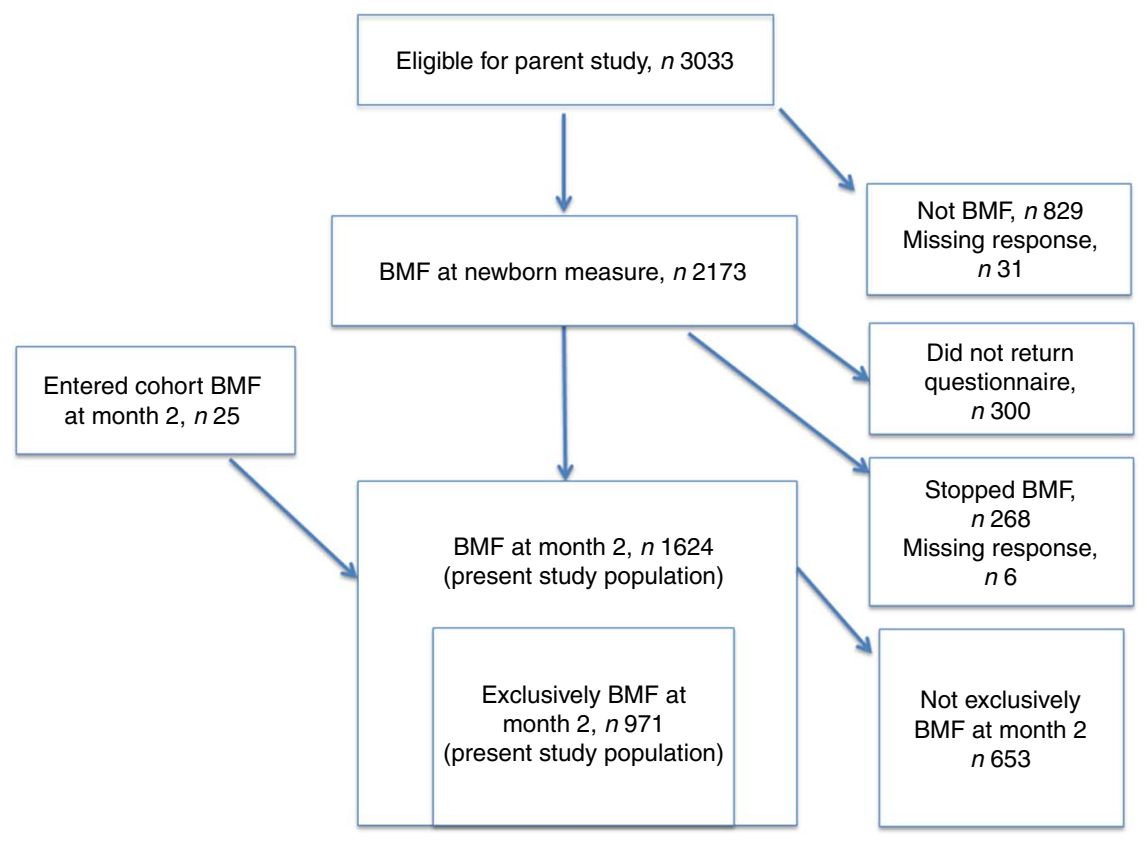

Fig. 1 Participation flowchart for study populations (BMF, breast-milk feeding) 


\section{Outcome assessment}

Although there is a growing body of research that distinguishes between feeding at breast and expressing breast milk for feeding ${ }^{(12)}$, the IFPS II did not collect those data. Therefore, 'BMF' in the present study encompasses both practices. The main outcomes of interest were time to cessation of BMF (including exclusive and partial) and exclusive BMF. Women who continued BMF for at least the recommended duration were censored at the time of reaching the recommended duration (6 months for exclusive $\mathrm{BMF}$ and 12 months for BMF) ${ }^{(3)}$. Each monthly questionnaire contained a module for mothers to complete when they had stopped all breast-feeding and pumping. Respondents indicated infant age when the mother stopped breast-feeding and pumping milk (not necessarily when the infant stopped receiving breast milk). Thus, BMF duration for the current analysis is a measure of the mother's practice. The Centers for Disease Control and Prevention imputed missing values for BMF duration (approximately 6\% of original study population $)^{(14)}$, which we used in our analysis. If a mother dropped out of the study, then she was censored and her BMF duration was recorded as her infant's age at the time of the last completed survey.

Exclusive BMF was measured on each monthly questionnaire through a series of questions about food consumption $^{(14)}$. We used the IFPS II data set variable for exclusive BMF duration that estimates the mid-point of infant age on the last questionnaire on which the mother indicated exclusive BMF and on the first questionnaire that indicated she was not exclusively BMF. If a mother dropped out of the study, then she was censored and her exclusive BMF duration was recorded as her infant's age at the time of the last completed survey.

\section{Analysis}

To identify appropriate confounders, we created a directed acyclic graph (DAG) ${ }^{(16)}$, informed by literature, expert consultation and the Theory of Planned Behaviour ${ }^{(17)}$ (Dagitty version 2.3). The variables we identified are described in detail in the online supplementary material, Table S1, and include: household income, maternal education, maternal race/ethnicity, previous breastfeeding experience, prenatal intention to breast-feed, childcare plans, planning to return to work, breast-feeding initiation and early practices (index of equally weighted practices in the hospital or birth centre that could affect breast-feeding: pacifier use, breast-feeding within the first hour, feeding other substances to infant, rooming in, breast-feeding support, referral for postpartum support, formula gift bag), professional breast-feeding support if needed, work, childcare arrangement, infant age when mother returned to work, work environment (index of equally weighted unfavourable experiences: negative comments from co-worker; negative comments from supervisor; difficulty arranging break time, place to pump or place to store milk; difficulty carrying pumping equipment; worry about keeping job because of breastfeeding; worry about continuing to breast-feed because of job; embarrassed among co-workers or supervisor) and workplace support. We also tested for effect measure modification by obesity, income, work environment and workplace support. About $20 \%$ of respondents were missing values for more than one covariate.

We conducted all statistical analyses with the statistical software package SAS version 9.4. We used multiple imputation with 100 replications to address the missing exposure and covariate values, using confounders, potential effect measure modifiers and selection factors (described below) as predictors. That imputation enabled us to retain the entire cohort in the analyses until they experienced the outcome or were censored. To control confounding from the large number of identified covariates, we created inverse probability (IP) of exposure weights, using methods recommended by Cole and Hernán ${ }^{(18)}$.

To address potential selection bias, we used two kinds of additional weights. The present study began at month 2 because that was when the exposure (regular pumping) was reported and, therefore, excludes women who stopped BMF before then. To address potential bias caused by that exclusion, we created and applied IP of selection weights using methods similar to those reported by Bengtson et al. ${ }^{(19)}$. To create those weights, we considered covariates associated with BMF and exclusive BMF at month 2 and then estimated the selection weights as the IP of BMF (and exclusive BMF, separately), with these predictors in the weights equation for BMF: maternal age, college degree, experience of breast-feeding-related pain in the first 2 weeks, marital status and plans to return to work within the first 9 weeks. Selection weights for exclusive BMF included all the predictors for BMF except maternal age because it was not statistically significant at $\alpha=0.05$. We stabilized the weights by the marginal probability of BMF or exclusive BMF at month 2, which reduced the weights at the extremes, i.e. for exposed women with a low probability of exposure, and the converse $^{(20)}$. In addition, about $20 \%$ of observations were lost to follow-up. We created and applied time-varying IP dropout weights to address possible selection bias due to loss to follow-up ${ }^{(21)}$. All weights were created in the imputed data set.

We used Cox proportional hazards regression models for the outcome assessed at months 2-12 (BMF) and months 2-6 (exclusive BMF) to estimate the hazard ratio (HR) for BMF cessation according to pumping status in the imputed data set. We then stratified the analyses by work status. Women were considered to be working if they answered: 'Did you work for pay any time during the past 4 weeks?' on the month 2 survey $^{(15)}$ affirmatively. Finally, we computed crude Kaplan-Meier curves with the unimputed data set to illustrate the probability of BMF for the exposure groups over time. 


\section{Results}

Most regular pumpers who were BMF at month 2 were married, white, not working (i.e. did not work for pay any time in the past 4 weeks), and had previous breast-feeding experience and a college degree (Table 1). In addition, most were working at the time of study enrolment (third trimester), had childcare plans for when they would be separated from their infants for feeding, and reported pumping so that someone else could feed their infants. Most non-regular/ non-pumpers who were BMF had profiles similar to those of regular pumpers, except that most of the former were not working at the time of study enrolment and had childcare plans in which mother and infant were not separated for feeding. Sixty per cent of non-regular/non-pumpers occasionally pumped, and most of them pumped so that someone else could feed their infants. Regular and non-regular/ non-pumpers who were exclusively BMF had similar profiles to women in the BMF groups (Table 1).

The crude Kaplan-Meier curve for BMF diverged by pumping status at about 13 weeks, showing a lower probability of BMF for women who pumped regularly compared with women who did not (Fig. 2). The crude curves stratified by work status also diverged at about 13 weeks, showing that women who neither worked nor pumped regularly had the highest probability of BMF, followed by women who worked but did not pump regularly, women who both worked and pumped regularly, and women who did not work but pumped regularly (Fig. 2). The crude KaplanMeier curves for exclusive BMF showed a divergence at about 9 weeks, with regular pumpers having a lower probability of exclusively BMF at every subsequent time point compared with non-regular/non-pumpers (Fig. 3). The crude curves stratified by work status also diverged at about 9 weeks, with regular pumpers who were not working having the lowest probability of exclusively BMF, while the other groups had cessation rates similar to one another.

In the first weighted Cox proportional hazards regression model, regular pumpers had an increased hazard of early BMF cessation ( $\mathrm{HR}=1.62 ; 95 \% \mathrm{CI} 1.47,1.78$; Table 2) compared with non-regular/non-pumpers. When stratified by working status, the estimated effect of regular pumping on time to BMF cessation was close to the null among working women $(\mathrm{HR}=0.90 ; 95 \% \mathrm{CI} 0.75,1.07)$, but was two times higher among non-working women $(\mathrm{HR}=2 \cdot 05$; $95 \%$ CI $1.84,2 \cdot 28)$. In the second weighted Cox proportional hazards regression model, regular pumpers had an increased hazard of early exclusive BMF cessation ( $\mathrm{HR}=1 \cdot 14$; $95 \% \mathrm{CI}$ 1.03, 1.25; Table 2) compared with non-regular/non-pumpers. When stratified by working status, the estimated effect of regular pumping on time to exclusive BMF cessation was higher than in non-regular/non-pumping among working women $(\mathrm{HR}=1 \cdot 14 ; 95 \% \mathrm{CI} 0 \cdot 96,1 \cdot 36)$, but the $\mathrm{CI}$ includes the null value. There was a similar result among nonworking women (HR $=1 \cdot 10 ; 95 \%$ CI 0.98, 1.22). Thus, while the overall estimated effect of early pumping on time to exclusive BMF cessation was significant, stratification by work indicated a null estimated effect for both groups.

Of the four variables tested, only work environment was a statistically significant effect measure modifier $(P<0.05)$ and only for exclusive BMF. Regular pumpers who had no unfavourable experiences at work had an increased hazard of exclusive BMF cessation compared with non-regular/nonpumpers $(\mathrm{HR}=1.31 ; 95 \%$ CI 1.03, 1.66). For working women who regularly pumped and had unfavourable experiences at work, the estimated effect of regular pumping on time to exclusive BMF cessation was lower than in nonregular/non-pumping among working women $(\mathrm{HR}=0 \cdot 82$; 95\% CI $0 \cdot 61,1 \cdot 10$ ), but the CI includes the null value.

When we reviewed the characteristics of regular pumpers, we found that $45 \%$ who BMF and did not work at month 2 had planned to return to work in the first year (see online supplementary material, Table S2). While $11 \%$ of nonworking regular pumpers had a high depression score, $6 \%$ of working, regular pumpers had a high depression score. The reasons for pumping among working and non-working regular pumpers were generally similar. Among nonworking regular pumpers: $76 \%$ pumped for someone else to feed the baby; $56 \%$ pumped to have an emergency supply; $46 \%$ pumped to increase supply; $46 \%$ did not want to breast-feed or infant could not breast-feed; $40 \%$ pumped to relieve engorgement; and $27 \%$ pumped to maintain supply when separated or infant was ill. Among working, regular pumpers: $85 \%$ pumped for someone else to feed the baby; $47 \%$ pumped to maintain supply when separated or infant was ill; $37 \%$ pumped to have an emergency supply; $34 \%$ did not want to breast-feed or infant could not breastfeed; and $32 \%$ pumped to relieve engorgement (Table S2).

For those exclusively BMF, 33\% who did not work at month 2 had planned to return to work in the first year, and nearly half (48\%) had not planned to return to work in the first year. Reasons for regularly pumping at month 2 among women who exclusively BMF were similar by work status. Non-working women reported regularly pumping for someone else to feed the baby ( $82 \%$ ); to have an emergency supply of breast milk (68\%); to increase milk supply (46\%); to relieve engorgement ( $40 \%$ ); because they did not want to breast-feed or infant could not (39\%); and to maintain supply when separated or infant was ill (25\%). Among working, regular pumpers: $90 \%$ pumped for someone else to feed the baby; $48 \%$ pumped to have an emergency supply of breast milk; 43\% pumped to maintain supply when separated or infant was ill; $41 \%$ pumped to increase milk supply; $32 \%$ pumped to relieve engorgement; and $32 \%$ pumped because they did not want to breast-feed or infant could not breastfeed (see online supplementary material, Table S2).

\section{Discussion}

The present study estimated the effect of regular breastmilk pumping in the early postpartum period on 
Table 1 Maternal and infant descriptive characteristics for 1624 women who reported breast-milk feeding (BMF) when they completed the month 2 questionnaire for the US Infant Feeding Practices Survey II (IFPS II), 2005-2007

\begin{tabular}{|c|c|c|c|c|c|c|c|c|}
\hline & \multicolumn{4}{|c|}{ Any BMF at 2 months $(n 1624)^{*}$} & \multicolumn{4}{|c|}{ Exclusive BMF at 2 months $(n$ 971)† } \\
\hline & \multicolumn{2}{|c|}{$\begin{array}{l}\text { Regularly pumping } \neq \\
\qquad(n 347)\end{array}$} & \multicolumn{2}{|c|}{$\begin{array}{l}\text { Not regularly pumping } \\
(n \text { 1235) }\end{array}$} & \multicolumn{2}{|c|}{$\begin{array}{l}\text { Regularly pumping } \neq \\
\qquad(n 199)\end{array}$} & \multicolumn{2}{|c|}{$\begin{array}{l}\text { Not regularly pumping } \\
(n \text { 754) }\end{array}$} \\
\hline & $n$ or Mean & $\%$ or SD & $n$ or Mean & $\%$ or SD & $n$ or Mean & $\%$ or SD & $n$ or Mean & $\%$ or SD \\
\hline $\begin{array}{l}\text { Maternal age at study } \\
\text { enrolment§ (years) }\end{array}$ & $29 \cdot 6$ & 4.7 & $29 \cdot 7$ & $5 \cdot 2$ & $29 \cdot 6$ & 4.5 & $29 \cdot 7$ & $5 \cdot 0$ \\
\hline \multicolumn{9}{|l|}{ Household income (\$US) } \\
\hline Median range & \multicolumn{2}{|c|}{$45000-49999$} & \multicolumn{2}{|c|}{$40000-44999$} & \multicolumn{2}{|c|}{$45000-49999$} & \multicolumn{2}{|c|}{$40000-44999$} \\
\hline Education & & & & & & & & \\
\hline College graduate or more & 198 & 57 & 538 & 44 & 125 & 63 & 366 & 49 \\
\hline Some college or less & 135 & 39 & 644 & 52 & 74 & 37 & 367 & 49 \\
\hline Missing & 14 & 4 & 53 & 4 & 0 & 0 & 6 & 1 \\
\hline \multicolumn{9}{|l|}{ Race/ethnicity } \\
\hline White, non-Hispanic & 284 & 82 & 1051 & 85 & 164 & 82 & 665 & 88 \\
\hline Black, non-Hispanic & 14 & 4 & 36 & 3 & 9 & 5 & 15 & 2 \\
\hline Hispanic & 19 & 6 & 72 & 6 & 11 & 6 & 32 & 4 \\
\hline Other & 20 & 6 & 54 & 4 & 8 & 4 & 31 & 4 \\
\hline Missing & 10 & 3 & 22 & 2 & 7 & 4 & 11 & 1 \\
\hline \multicolumn{9}{|l|}{ Parity } \\
\hline No. of other babies & 0.9 & 1.0 & 1.4 & $1 \cdot 3$ & 0.9 & 1.0 & 1.4 & 1.2 \\
\hline Missing & 8 & 2 & 16 & 1 & 4 & 2 & 7 & 1 \\
\hline \multicolumn{9}{|l|}{ Marital status } \\
\hline Married & 281 & 81 & 1023 & 83 & 165 & 83 & 670 & 89 \\
\hline Single/divorced/separated & 50 & 15 & 174 & 13 & 26 & 13 & 64 & 9 \\
\hline Missing & 16 & 5 & 48 & 4 & 1 & 1 & 5 & 1 \\
\hline Previous breast-feeding experie & & & & & & & & \\
\hline Yes & 186 & 53 & 904 & 74 & 103 & 52 & 578 & 77 \\
\hline No & 149 & 44 & 304 & 24 & 88 & 45 & 163 & 22 \\
\hline Missing & 12 & 3 & 27 & 2 & 8 & 4 & 13 & 2 \\
\hline Maternal BMI (pre-pregnancy) & & & & & & & & \\
\hline Underweight & 11 & 3 & 50 & 4 & 7 & 4 & 35 & 5 \\
\hline Normal & 169 & 49 & 589 & 48 & 102 & 51 & 387 & 51 \\
\hline Overweight & 104 & 30 & 305 & 25 & 56 & 28 & 178 & 24 \\
\hline Obese & 61 & 17 & 276 & 22 & 33 & 17 & 146 & 19 \\
\hline Missing & 2 & 1 & 15 & 1 & 1 & 1 & 8 & 1 \\
\hline Working at time of study enrolm & & & & & & & & \\
\hline Yes & 253 & 73 & 531 & 43 & 148 & 74 & 299 & 40 \\
\hline No & 90 & 26 & 687 & 56 & 49 & 25 & 445 & 59 \\
\hline Missing & 4 & 1 & 17 & 1 & 2 & 1 & 10 & 1 \\
\hline Prenatal intention to breast-feed $\|$ & & & & & & & & \\
\hline Months & & & & & & & & \\
\hline Missing & 9 & 3 & 99 & 8 & 24 & 12 & 78 & 10 \\
\hline Childcare plans & & & & & & & & \\
\hline Mother/infant together & 97 & 27 & 753 & 61 & 56 & 27 & 505 & 67 \\
\hline Mother/infant separated & 201 & 58 & 331 & 27 & 115 & 58 & 153 & 20 \\
\hline Combination/not sure & 47 & 14 & 143 & 12 & 27 & 14 & 89 & 12 \\
\hline Missing & 2 & 1 & 8 & 1 & 1 & 1 & 7 & 1 \\
\hline Planning to return to work & & & & & & & & \\
\hline Within 9 weeks & 155 & 45 & 316 & 26 & 88 & 44 & 154 & 20 \\
\hline $\begin{array}{l}\text { After } 9 \text { weeks but within first } \\
\text { year }\end{array}$ & 114 & 33 & 296 & 24 & 68 & 34 & 175 & 23 \\
\hline $\begin{array}{l}\text { Not planning to return in first } \\
\text { year }\end{array}$ & 75 & 22 & 612 & 50 & 41 & 21 & 416 & 55 \\
\hline Missing & 3 & 1 & 11 & 1 & 2 & 1 & 9 & 1 \\
\hline Breast-feeding initiation and ear & practices & & & & & & & \\
\hline Mean score & $3 \cdot 1$ & 1.4 & $3 \cdot 1$ & 1.5 & $2 \cdot 9$ & 1.4 & $2 \cdot 9$ & 1.4 \\
\hline Missing & 9 & 3 & 36 & 3 & 3 & 2 & 25 & 3 \\
\hline Late preterm status & & & & & & & & \\
\hline Yes & 18 & 5 & 36 & 3 & 9 & 5 & 12 & 2 \\
\hline No & 329 & 95 & 1199 & 97 & 190 & 95 & 742 & 98 \\
\hline Breast-feeding problems & & & & & & & & \\
\hline No & 41 & 11 & 165 & 13 & 25 & 13 & 122 & 16 \\
\hline Yes & 304 & 88 & 1061 & 86 & 174 & 87 & 632 & 84 \\
\hline Got help & 204 & 59 & 582 & 47 & 114 & 57 & 299 & 40 \\
\hline Did not get help & 99 & 29 & 479 & 39 & 60 & 30 & 330 & 44 \\
\hline Missing & 1 & 0 & 9 & 1 & 0 & 0 & 3 & 0 \\
\hline
\end{tabular}




\begin{tabular}{|c|c|c|c|c|c|c|c|c|}
\hline & \multicolumn{4}{|c|}{ Any BMF at 2 months $(n 1624)^{\star}$} & \multicolumn{4}{|c|}{ Exclusive BMF at 2 months $(n$ 971)† } \\
\hline & \multicolumn{2}{|c|}{$\begin{array}{l}\text { Regularly pumping } \neq \\
\qquad(\text { n 347) }\end{array}$} & \multicolumn{2}{|c|}{$\begin{array}{l}\text { Not regularly pumping } \\
(\text { (n 1235) }\end{array}$} & \multicolumn{2}{|c|}{$\begin{array}{l}\text { Regularly pumping } \neq \\
\qquad(n 199)\end{array}$} & \multicolumn{2}{|c|}{$\begin{array}{c}\text { Not regularly pumping } \\
(n 754)\end{array}$} \\
\hline & $n$ or Mean & $\%$ or SD & $n$ or Mean & $\%$ or SD & $n$ or Mean & $\%$ or SD & $n$ or Mean & $\%$ or SD \\
\hline \multicolumn{9}{|l|}{ Postpartum depression } \\
\hline Mean score & $6 \cdot 3$ & $4 \cdot 2$ & 6.6 & 4.5 & 5.9 & $4 \cdot 1$ & $6 \cdot 0$ & $4 \cdot 2$ \\
\hline Score $\geq 13^{\star *}$ & 29 & 8 & 117 & 9 & 14 & 7 & 51 & 7 \\
\hline Score $<13$ & 310 & 89 & 1082 & 88 & 179 & 90 & 683 & 91 \\
\hline Missing & 8 & 2 & 36 & 3 & 6 & 3 & 20 & 3 \\
\hline \multicolumn{9}{|l|}{ Workingt† } \\
\hline Yes & 161 & 46 & 251 & 20 & 88 & 44 & 130 & 17 \\
\hline No & 182 & 52 & 920 & 75 & 111 & 56 & 590 & 78 \\
\hline Missing & 4 & 1 & 64 & 5 & 0 & 0 & 34 & 5 \\
\hline $\begin{array}{l}\text { Reasons for pumping in past } \\
2 \text { weeks } \ddagger \ddagger\end{array}$ & 347 & 100 & 741 & 60 & 199 & 100 & 468 & 62 \\
\hline Engorgement & 126 & 36 & 318 & 43 & 72 & 36 & 190 & 41 \\
\hline Sore nipples & 13 & 4 & 33 & 4 & 11 & 6 & 11 & 0 \\
\hline Increase milk supply & 155 & 45 & 202 & 27 & 87 & 44 & 99 & 21 \\
\hline $\begin{array}{l}\text { For someone else to feed } \\
\text { baby }\end{array}$ & 278 & 80 & 456 & 62 & 170 & 85 & 313 & 67 \\
\hline $\begin{array}{l}\text { Does not want to breast-feed } \\
\text { or infant cannot }\end{array}$ & 140 & 40 & 192 & 26 & 71 & 36 & 100 & 21 \\
\hline $\begin{array}{l}\text { To maintain supply when } \\
\text { infant could not nurse } \\
\text { (separation or infant illness) }\end{array}$ & 127 & 37 & 160 & 22 & 66 & 33 & 74 & 16 \\
\hline To mix with food & 20 & 6 & 22 & 3 & 2 & 1 & 9 & 2 \\
\hline To donate & 4 & 1 & 1 & 0 & 3 & 2 & 0 & \\
\hline $\begin{array}{l}\text { To have an emergency } \\
\text { supply }\end{array}$ & 164 & 47 & 293 & 40 & 117 & 59 & 221 & 47 \\
\hline Missing & 17 & 1 & 4 & 1 & 1 & 1 & 9 & 2 \\
\hline \multicolumn{9}{|l|}{ Childcare arrangement } \\
\hline $\begin{array}{l}\text { Mother and infant are } \\
\text { sometimes separated for } \\
\text { feeding }\end{array}$ & 138 & 40 & 109 & 10 & 75 & 38 & 43 & 6 \\
\hline $\begin{array}{l}\text { Mother and infant are never } \\
\text { separated for feeding }\end{array}$ & 20 & 6 & 126 & 10 & 13 & 7 & 83 & 11 \\
\hline Missing & 4 & 1 & 64 & 5 & 0 & 0 & 34 & 5 \\
\hline Not working & 182 & 52 & 920 & 75 & 111 & 56 & 590 & 78 \\
\hline \multicolumn{9}{|l|}{ Hostile work environment } \\
\hline Mean scoreף & $1 \cdot 2$ & 1.6 & 0.6 & 1.3 & $1 \cdot 2$ & 1.7 & 0.5 & $1 \cdot 1$ \\
\hline Missing & 34 & 21 & 50 & 20 & 17 & 19 & 20 & 15 \\
\hline Not working & 182 & 52 & 920 & 75 & 111 & 56 & 590 & 78 \\
\hline \multicolumn{9}{|c|}{ Infant age when mother returned to work } \\
\hline$<9$ weeks & 109 & 31 & 155 & 13 & 57 & 29 & 83 & 11 \\
\hline$\geq 9$ weeks & 26 & 7 & 61 & 5 & 17 & 9 & 31 & 4 \\
\hline Missing & 30 & 9 & 99 & 8 & 14 & 7 & 50 & 7 \\
\hline Not working & 182 & 52 & 920 & 74 & 111 & 56 & 590 & 78 \\
\hline \multicolumn{9}{|l|}{ Workplace support } \\
\hline Not at all supportive & 5 & 1 & 6 & 0 & 2 & 1 & 2 & 0 \\
\hline Not too supportive & 14 & 4 & 13 & 1 & 8 & 4 & 3 & 0 \\
\hline Somewhat supportive & 41 & 12 & 39 & 3 & 19 & 10 & 18 & 2 \\
\hline Very supportive & 75 & 22 & 152 & 12 & 46 & 23 & 91 & 12 \\
\hline Missing & 26 & 7 & 41 & 3 & 13 & 7 & 50 & 7 \\
\hline Not working & 182 & 52 & 920 & 75 & 111 & 56 & 590 & 78 \\
\hline $\begin{array}{l}\text { Breast-milk feeding duration } \\
\text { (weeks) }\end{array}$ & 32.5 & $15 \cdot 5$ & $37 \cdot 2$ & $16 \cdot 4$ & $15 \cdot 2$ & $6 \cdot 3$ & $16 \cdot 6$ & 6.9 \\
\hline
\end{tabular}

${ }^{*}$ Missing, $n 6$.

†Missing, $n$ 13; exclusive breast-feeding is a subset of any breast-feeding.

‡Missing, $n$ 42.

SWomen enrolled during the third trimester.

Measured in months for any BMF (median reported) and by month range for exclusive BMF.

TVariable composition described in the online supplementary material, Table S1.

${ }^{\star *}$ Referral for depression treatment is recommended for score of 13 or higher on the Edinburgh Postpartum Depression Screening tool.

††Worked sometime in the past 4 weeks, from time completed month 2 questionnaire.

$\ddagger \ddagger$ This is the denominator (those who had pumped) for the list of reasons pumped. Respondents could choose more than one reason. 
(a)

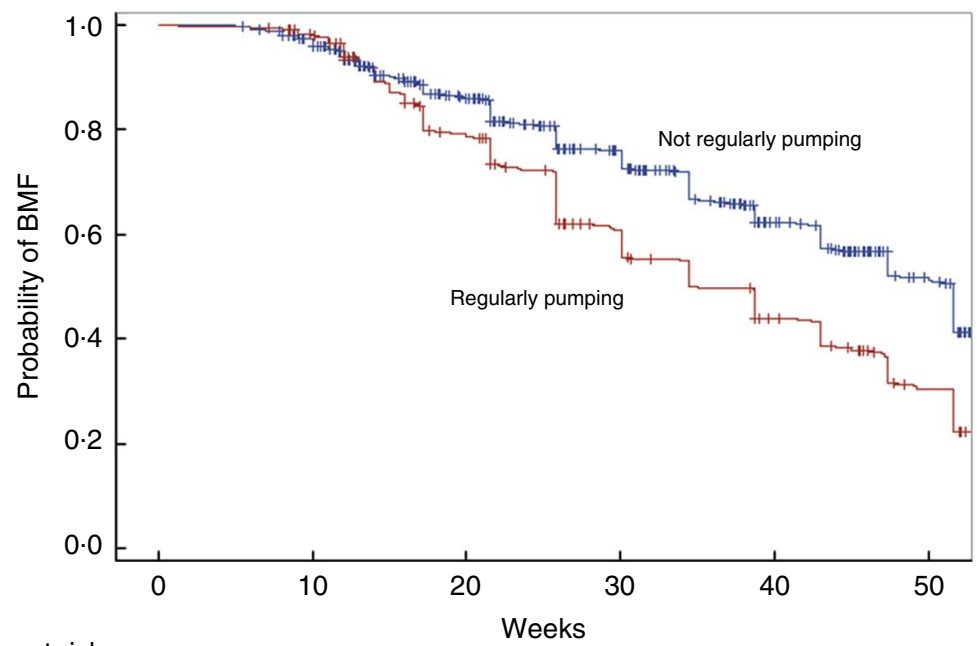

\begin{tabular}{rrrrrrr} 
No. at risk & \multicolumn{7}{c}{. } & & & \\
Not regularly pumping & 1235 & 1166 & 975 & 810 & 616 & 462 \\
Regularly pumping & 347 & 335 & 252 & 180 & 124 & 77
\end{tabular}

(b)

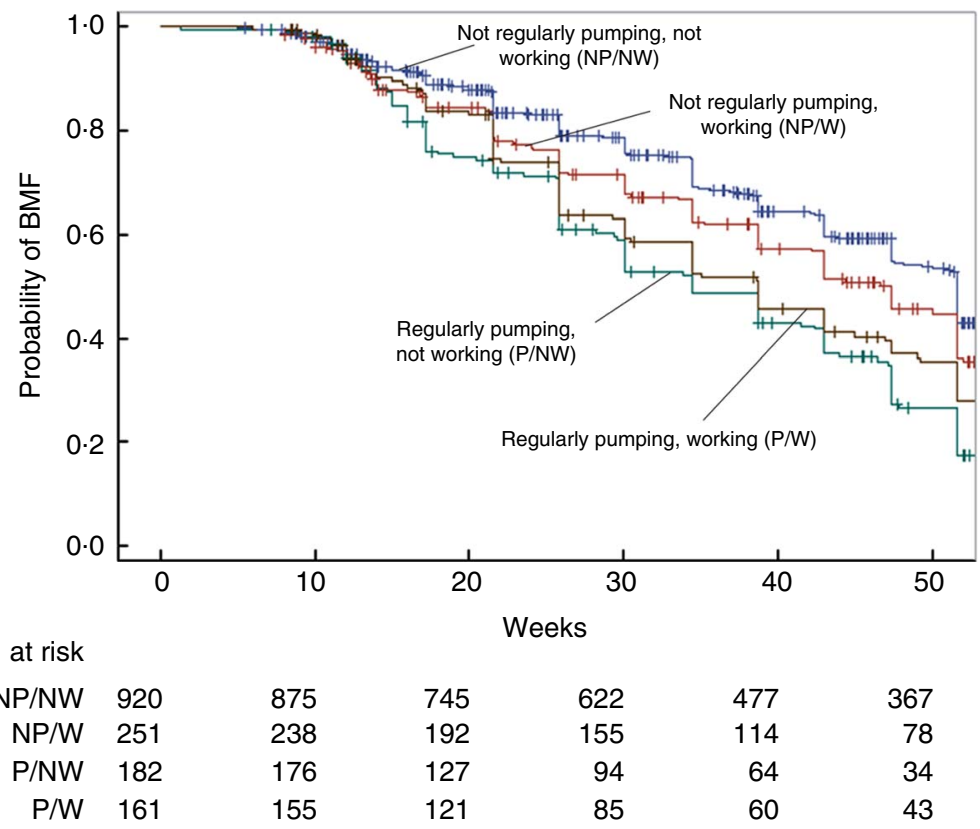

Fig. 2 (colour online) Kaplan-Meier curves (+, censored) for 1624 women in the US Infant Feeding Practices Survey II (IFPS II) feeding breast milk to their infants, by (a) pumping practice and (b) work status, 2005-2007. (a) Crude curves computed from unimputed data set; forty-two observations missing ( $<3 \%$ ); log rank $P<0.0001$; (b) crude curves computed from unimputed data set; 110 observations missing $(<7 \%)$; log rank $P<0.0001$ (BMF, breast-milk feeding)

time to BMF and exclusive BMF cessation, up to the recommended durations (12 months and 6 months, respectively), among working and non-working women in the USA. We found that regular pumpers were more than $60 \%$ more likely to stop BMF, and nearly $15 \%$ more likely to stop exclusive BMF, than non-regular/non-pumpers, within the recommended time frames. Work status modified the association only for women who BMF. Among working women who BMF, regular pumping had a nearly null estimated effect; however, non-working women who regularly pumped were more than twice as likely to stop BMF as non-regular/non-pumpers. Among working women who exclusively BMF, our findings suggested an elevated hazard for regular pumping compared with non-regular/not pumping, although the CI included the null. There was a similar estimation for nonworking women who exclusively BMF.

These results suggest that regular pumpers in the early postpartum period may be more likely to stop BMF than their non-regular pumping counterparts and may need specialized support to BMF for the recommended duration. In particular, regular pumpers who are not working 
(a)

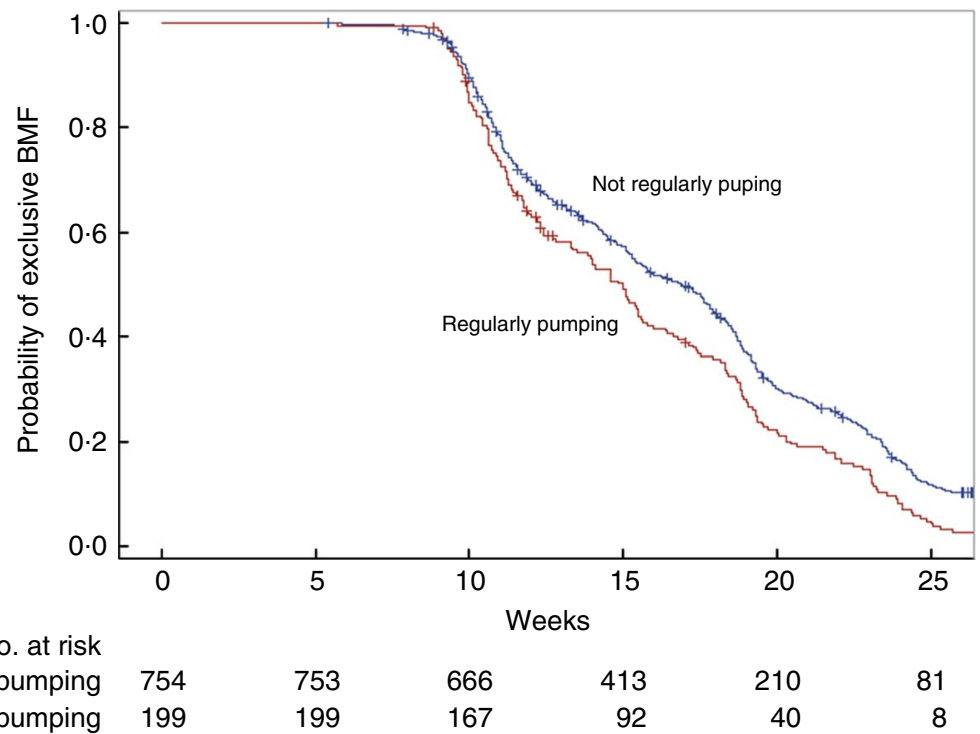

(b)

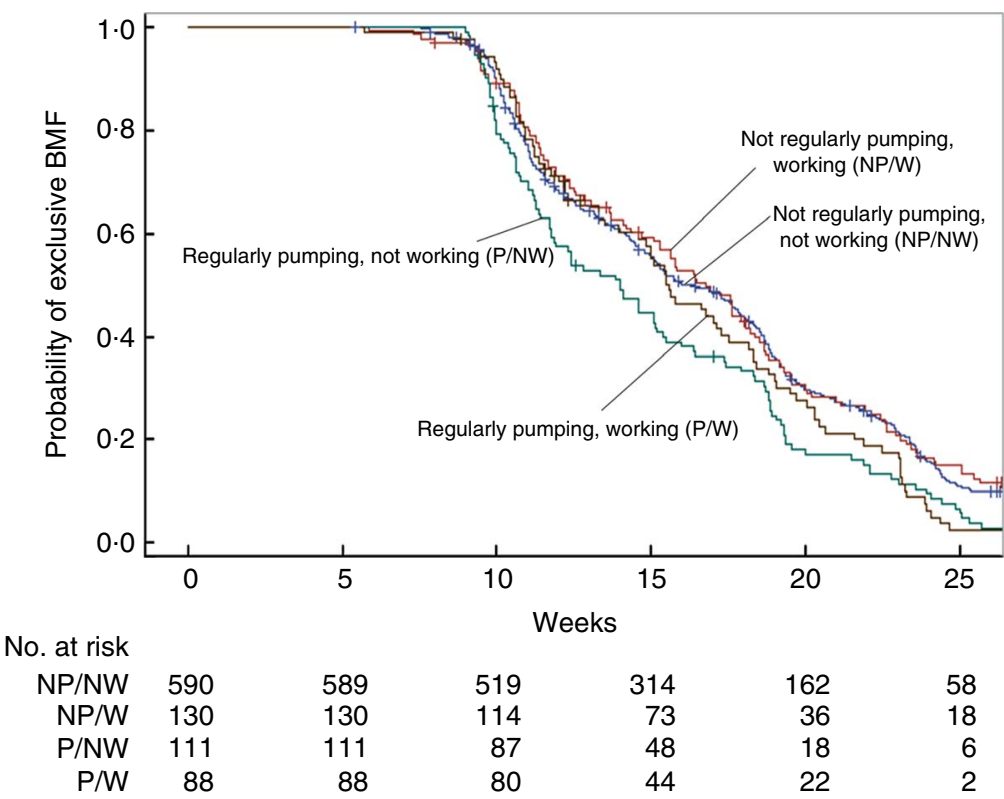

Fig. 3 (colour online) Kaplan-Meier curves (+, censored) for 971 women in the US Infant Feeding Practices Survey II (IFPS II) exclusively feeding breast milk to their infants, by (a) pumping practice and (b) work status, 2005-2007. (a) Crude curves computed from unimputed data set; eighteen observations missing ( $<2 \%$; $\log$ rank $P=0.0004$; (b) crude curves computed from unimputed data set; fifty-two observations missing $(<6 \%)$; log rank $P=0.0062$ (BMF, breast-milk feeding)

may need support. Further, regular pumping, as opposed to non-regular or not pumping, may neither help nor hinder working women's BMF and exclusive BMF durations, despite policy intentions to support breast-feeding through breast pumping ${ }^{(11)}$ and national goals to increase BMF duration ${ }^{(22)}$. This finding suggests that workplace protections of BMF that focus mainly on pumping may not be effective in increasing BMF and exclusive BMF durations for working women.

One explanation for the observed association between pumping and early cessation of BMF could be that women who pumped to build a supply of expressed milk planned to use that supply to continue BMF after they returned to work. They may have intended to pump less often than their infants' feeding patterns, or not at all, at work. Not removing milk at regular intervals during the workday would eventually decrease supply ${ }^{(23)}$, which could lead to BMF cessation. Many regular pumpers who were not working at month 2 had planned to return to work within the first year. Most regular pumpers in the present study cited reasons for pumping that could be related to employment ${ }^{(24)}$, although that was not specified. Overall, several categories of 'reasons for pumping' overlap and it is difficult to distinguish between them, e.g. 'pumping for 
Table 2 Hazard ratios (HR) for the effect of regularly pumping, recorded at 2 months after birth, compared with not regularly pumping, on time to stopping breast-milk feeding (BMF) within 12 months postpartum, for 1624 women BMF at 2 months in the US Infant Feeding Practices Survey II (IFPS II), 2005-2007

\begin{tabular}{|c|c|c|c|c|c|c|}
\hline & \multirow[b]{2}{*}{$\begin{array}{l}\text { No. regularly } \\
\text { pumping }\end{array}$} & \multirow[b]{2}{*}{$\begin{array}{l}\text { No. not regularly } \\
\text { pumping }\end{array}$} & \multicolumn{2}{|c|}{ Crude $^{\star}, \dagger$} & \multicolumn{2}{|c|}{ Weighted $\ddagger$} \\
\hline & & & HR & $95 \% \mathrm{Cl}$ & $\mathrm{HR}$ & $95 \% \mathrm{Cl}$ \\
\hline \multicolumn{7}{|l|}{ BMF (n 1624) } \\
\hline \multicolumn{7}{|l|}{ Work status $\|$} \\
\hline Working & 161 & 251 & $1 \cdot 17$ & $1.01,1.35$ & 0.90 & $0.75,1.07$ \\
\hline Not working & 182 & 920 & 2.02 & $1 \cdot 80,2 \cdot 27$ & 2.05 & $1 \cdot 84,2 \cdot 28$ \\
\hline $\begin{array}{l}\text { Overall } \\
\text { Work status**}\end{array}$ & 199 & 754 & $1 \cdot 31$ & $1 \cdot 20,1.43$ & $1 \cdot 14$ & $1.03,1.25$ \\
\hline $\begin{array}{l}\text { Working } \\
\text { Not working }\end{array}$ & $\begin{array}{r}88 \\
111\end{array}$ & $\begin{array}{l}130 \\
590\end{array}$ & $\begin{array}{l}1.47 \\
1.20\end{array}$ & $\begin{array}{l}1.27,1.70 \\
1.06,1.36\end{array}$ & $\begin{array}{l}1 \cdot 14 \\
1.10\end{array}$ & $\begin{array}{l}0.96,1.36 \\
0.98,1.22\end{array}$ \\
\hline
\end{tabular}

*BMF: weighted for selection (mean $=0.98$; range $0.69-5.72)$ and loss to follow-up (mean =0.99; range 0.27-3.46) in imputed data set.

$\dagger$ Exclusive BMF: weighted for selection (mean=1.00; range 0.48-7.54) and loss to follow-up (mean=1.00; range 0.10-4.99) in imputed data set.

$\ddagger$ Weighted to control for confounding by household income, education, white race/ethnicity, prenatal breast-feeding intention, childcare plan, plan to return to

work within 9 weeks, early breast-feeding practices, accessing help for breast-feeding problems, infant age when mother returned to work, mother-infant sometimes separated for feeding, work, late preterm status, work environment and workplace support. Also weighted for selection and loss to follow-up in imputed data set: BMF weights (mean=0.98; range 0.24-8.66); exclusive BMF weights (mean =1.00; range 0.21-17.64).

§Missing, $n 42(<3 \%)$.

||Reported on month 2 questionnaire; missing, $n 68(<5 \%)$.

TMissing, $n 18(<2 \%)$.

${ }^{*}$ Reported on month 2 questionnaire; missing, $n 34(<4 \%)$.

someone else to feed the infant' and 'to maintain supply when infant could not nurse due to separation or infant illness', both of which could be related to working. Thus, the utility of the information pertaining to reasons for pumping is limited.

The fact that regular pumping was not associated with BMF and exclusive BMF cessation among working women in our study was somewhat surprising; we had expected to find either a protective effect on duration, as reported by Meehan et $a l^{(10)}$, or a detrimental effect, as reported by Felice $e t a l .{ }^{(12)}$. Our finding may represent the statistical equalizing of two different strategies for BMF at month 2 in this population. The first strategy, mentioned above in the context of women who were not working at month 2 , could also apply to women working at month 2 , with the same consequence through the aforementioned biological mechanism. The second strategy, pumping at work, could lead to early cessation for some but not others, due to: a biological mechanism through which repeated ineffective $^{(23)}$ or infrequent milk removal could decrease supply ${ }^{(25)}$; a reluctance to pump due to the psychological and logistical burdens of carrying pumping supplies and equipment, and of negotiating time and space for pumping during the workday and cleaning pump parts, as well as milk storage; or unknown factors.

Our findings suggested a detrimental effect of regular pumping for women who reported no unfavourable experiences at work, which is consistent with our overall finding: regular pumpers were more likely to stop exclusive BMF compared with non-regular pumpers. We observed no effect of regular pumping compared with non-regular pumping for women with unfavourable experiences at work. There is currently no literature that sheds light on this finding. Perhaps some women became more determined to persist when faced with obstacles while others decided that pumping is not worth risking more unfavourable experiences. Further research on this topic is needed.

Our findings are particularly salient for the USA, which lacks basic maternity protections such as paid leave and affordable, high-quality childcare for all families. However, the USA supports breast-milk pumping as a way for mothers to continue BMF when they are separated from their infants due to work ${ }^{(11)}$. These data were collected in 2005-2007, before the Affordable Care Act introduced protections for breast-milk pumping in the workplace. Nevertheless, the present study provides some indication of expectations for the effect of regular pumping on BMF duration. Breast-feeding rates in the USA have increased slightly over the past decade ${ }^{(26)}$ and pump ownership has increased under the Affordable Care Act ${ }^{(27)}$. However, persistent gaps in coverage of breast-feeding support remain $^{(27,28)}$, underscoring the importance of understanding how breast pumping affects BMF duration.

Our findings align with the results of another study using data from the IFPS $\mathrm{II}^{(12)}$, which reported that a greater frequency of pumping was associated with stopping BMF. A different study with IFPS II data reported that women who pumped at work had longer BMF durations than those who neither pumped nor fed at breast during work time, but shorter BMF durations than women who only fed at breast, or both pumped and fed at breast during work time ${ }^{(29)}$. That study indicated some benefit for pumpers, although neither the regularity nor the frequency of pumping was considered ${ }^{(29)}$. Neither study used DAG analysis to determine an appropriate 
set of covariates for adjustment and thus may be biased from uncontrolled confounding, given the number of factors that affect both pumping and BMF duration throughout the perinatal and postpartum periods. Our DAG analysis did not reveal adjustment factors commonly used in breast-feeding studies, such as age and obesity, to be confounders for the effects we studied. In our DAG, age affects regular pumping through its effects on more proximal factors including prenatal intention, which was controlled in our statistical model via IP of exposure weights. Obesity affects regular pumping through its effects on more proximal factors including breast-feeding initiation and early practices, which was controlled in our statistical model via IP of exposure weights. We decided to control for more proximal factors to avoid 'overcontrol' and to fit a more parsimonious statistical model.

Prospective studies using data collected after the Affordable Care Act was enacted would provide a useful comparison to understand how its pumping protections may have changed the experiences of, as well as the BMF intensity (exclusive $v$. any) and durations, for working mothers. In particular, further research among women from various income levels and occupations, and who combine working with BMF using different strategies including minimizing maternal-infant separation, as some have recommended ${ }^{(29,30)}$, would be particularly useful.

Strengths of the current study included the use of IP weights to control confounding, which improved model parsimony. Under assumptions of positivity (i.e. a positive probability of each level of exposure at each covariate level), consistency, exchangeability and correct specification of the weights model, the parameters produced by a weighted regression model can estimate the average causal effect of early, regular pumping in our study population $^{(18)}$. For example, positivity assumes that each race/ethnicity category in the analysis (white and nonwhite) could include regular pumpers and non-regular pumpers. The characteristics of this study population (e.g. $>80 \%$ white race/ethnicity) led to certain 'blunt' categorization of some variables (e.g. race/ethnicity) to address potential problems with positivity. Our exposure is well defined in that there are not multiple versions of 'regular pumping in the first 8 weeks', as defined in this data set; however, 'regular' was not defined on the questionnaire or in other parent study materials. We believe that the model is correctly specified because we consulted literature and subject matter experts during the creation of the DAG. DAG theory maintains that appropriate analysis yields a minimally sufficient set of covariates to control confounding of the exposure-outcome relationship ${ }^{(16)}$. There was no unmeasured confounding, meaning that we have measured all of the confounders in the minimally sufficient adjustment set of covariates identified by the DAG; however, there is likely residual confounding from an unknown source, which is a common limitation to observational studies ${ }^{(21)}$. These same assumptions apply to non-weighting methods ${ }^{(18)}$.

We also used selection and dropout weights to address selection bias. There is still selection bias related to membership of consumer panels and meeting participation criteria for the parent study, which prevents generalization of these results to the US maternity population. The parent study population has been reported to be better off than the general maternity population in the USA ${ }^{(14)}$. Thus, our results may be a conservative estimate of the effect of regular pumping on time to BMF and exclusive BMF cessation in the general population, if the observed effect could be stronger for those with fewer resources.

There may be confounding by indication (a type of selection bias), meaning that women may not be included in this study because they decided not to BMF because they knew that they would be returning to work early and could not combine BMF with working. In addition, full- or part-time work status was not measured at month 2 , nor was the type of job reported. That information could have enabled an in-depth categorization of 'work'.

Further, some questionnaires were not completed at the intended time, resulting in possible misclassification or recall bias. Approximately $10 \%$ of women completed month 2 questionnaires more than 13 weeks after childbirth. The variation in time of questionnaire completion could have caused limited misclassification of work status. Exclusive BMF measurement assessed behaviour during the past $7 \mathrm{~d}$; it is assumed that this practice was constant for the remaining days of the month. This is a common but imperfect way to measure exclusive BMF practice. Finally, BMF cessation measures when the mother stopped breast-feeding and pumping milk, and not necessarily when the infant stopped receiving breast milk. Some infants probably continued to receive pumped milk, so the outcome is not fully aligned with the actual measurement.

\section{Public health implications}

Early, regular breast-milk pumping was associated with early BMF and exclusive BMF cessation, compared with non-regular or no pumping. It is critical to further evaluate the effect of pump provision and workplace policies, along with access to support, on BMF and exclusive BMF durations. Although the present study took place in the USA, its findings may be relevant for all countries with policies that encourage regular breast-milk pumping in the early postpartum period.

\section{Acknowledgements}

Acknowledgements: The authors thank the University of North Carolina's Breastfeeding Umbrella Study Team for advice on study design and variable specifications, Ann 
Von Holle for SAS coding advice and Rob Carty for assistance with figures. Financial support: This research received no specific grant from any funding agency in the public, commercial or not-for-profit sectors. Conflict of interest: None. Authorship: J.Y. designed the study, conducted the analyses and drafted the manuscript. All other authors contributed to the study design and interpretation of the results and provided substantive feedback on manuscript drafts. All authors approved this submission. Ethics of human subject participation: This is a secondary analysis of data from the Infant Feeding Practices Study II, a sample of pregnant women throughout the USA, with follow-up during the first year of life. We used the de-identified, publicly available data set, which was exempted from review by the Institutional Review Board of the University of North Carolina, Chapel Hill.

\section{Supplementary material}

To view supplementary material for this article, please visit https://doi.org/10.1017/S1368980017004281

\section{References}

1. Grummer-Strawn L \& Rollins N (2015) Summarising the health effects of breastfeeding. Acta Pediatr 104, 1-2.

2. US Department of Health and Human Services (2011) The Surgeon General's Call to Action to Support Breastfeeding. Washington, DC: US Department of Health and Human Services, Office of the Surgeon General.

3. American Academy of Pediatrics, Section on Breastfeeding Medicine (2012) Breastfeeding and the use of human milk. Pediatrics 129, e827-e841.

4. World Health Organization (2011) Exclusive breastfeeding for six months best for babies everywhere. http://www. who.int/mediacentre/news/statements/2011/breastfeeding_ 20110115/en/ (accessed November 2016).

5. Centers for Disease Control and Prevention (2016) Breastfeeding Data. http://www.cdc.gov/breastfeeding/data/nis_ data/ (accessed January 2017).

6. Bureau of Labor Statistics (2016) Table 6. Employment status of mothers with own children under 3 years old by single year of age of youngest child and marital status, 2014-2015 annual averages. http://www.bls.gov/news. release/famee.t06.htm (accessed September 2016).

7. Klerman JA, Daley K \& Pozniak A (2014) Family and Medical Leave in 2012: Technical Report. Cambridge, MA: Abt Associates, Inc.

8. Johns HM, Forster DA, Amir LH et al. (2013) Prevalence and outcomes in breast milk expressing in women with healthy term infants: a systematic review. BMC Pregnancy Childbirth 13, 212.

9. Rasmussen KM \& Geraghty S (2011) The quiet revolution: breastfeeding transformed with the use of breast pumps. Am J Public Health 101, 1356-1359.

10. Meehan K, Harrison GG, Afifi AA et al. (2008) The association between an electric pump loan program and the timing of requests for formula by working mothers in WIC. J Hum Lact 24, 150-158.

11. American Academy of Pediatrics (2013) Federal Support for Breastfeeding. Elk Grove Village, IL: American Academy of Pediatrics.
12. Felice JP, Cassano PA \& Rasmussen KM (2016) Pumping human milk in the early postpartum period: its impact on long-term practices for feeding at the breast and exclusively feeding human milk in a longitudinal survey cohort. Am J Clin Nutr 103, 1267-1277.

13. Fein SB, Labiner-Wolfe J, Shealy KR et al. (2008) Infant feeding practices study II: study methods. Pediatr 122, Suppl. 2, S28-S35.

14. Centers for Disease Control (2012) Infant Feeding Practices Study II: Data User Handbook. Atlanta, GA: Centers for Disease Control and Prevention.

15. Centers for Disease Control (2014) Infant Feeding Practices II: The Questionnaires. http://www.cdc.gov/breastfeeding/ data/ifps/questionnaires.htm (accessed September 2016).

16. Greenland S, Pearl J \& Robins JM (1999) Causal diagrams for epidemiologic research. Epidemiology 10, 37-48.

17. Bai Y, Wunderlich SM \& Fly AD (2011) Predicting intentions to continue exclusive breastfeeding for 6 months: a comparison among racial/ethnic groups. Matern Child Health J 15, 1257-1264.

18. Cole SR \& Hernán MA (2008) Constructing inverse probability weights for marginal structural models. Am J Epidemiol 168, 656-664.

19. Bengtson AM, Pence BW, Gaynes BN et al. (2016) Improving depression among HIV-infected adults: transporting the effect of a depression treatment intervention to routine care. J Acquir Immune Defic Syndr $\mathbf{7 3}$, 482-488.

20. Xu S, Ross C, Raebel M et al. (2010) Use of stabilized inverse propensity scores as weights to directly estimate relative risk and its confidence intervals. Value Health 13, 273-277.

21. Buchanan A, Hudgens M, Cole S et al. (2014) Worth the weight: using inverse probability weighted Cox models in AIDS research. AIDS Res Hum Retroviruses 30, $1170-1177$.

22. US Department of Health and Human Services, Office of Disease Prevention and Health Promotion (2017) Healthy People 2020 Goals. http://www.healthypeople.gov/2020/ topics-objectives/topic/maternal-infant-and-child-health/ objectives (accessed July 2017).

23. Mannel R \& Walker M (2013) Milk expression, storage, and handling. In Core Curriculum for Lactation Consultant Practice, pp. 621-640 [R Mannel, P Martens and M Walker, editors]. Burlington, MA: Jones \& Bartlett Learning, LLC.

24. Geraghty S, Davidson B, Tabangin M et al. (2012) Predictors of breastmilk expression by 1 month postpartum and influence on breastmilk feeding duration. Breastfeed Med $\mathbf{7}$, 112-117.

25. Baker G \& Lamb M (2013) Physiology of the breast during pregnancy and lactation. In Core Curriculum for Lactation Consultant Practice, pp. 287-300 [R Mannel, P Martens and $\mathrm{M}$ Walker, editors]. Burlington, MA: Jones \& Bartlett Learning, LLC.

26. Centers for Disease Control and Prevention (2017) Breastfeeding Report Cards. http://www.cdc.gov/breastfeeding/ data/reportcard.htm (accessed September 2017).

27. Hawkins SS, Noble A \& Baum CF (2017) Effect of the affordable care act on disparities in breastfeeding: the case of Maine. Am J Public Health 10, 1119-1121.

28. Kozhimannil KB, Jou J, Gjerdingen DK et al. (2016) Access to workplace accommodations to support breastfeeding after passage of the Affordable Care Act. Womens Health Issues 26, 6-13.

29. Fein SB, Mandal B \& Roe BE (2008) Success of strategies for combining employment and breastfeeding. Pediatrics $\mathbf{1 2 2}$, Suppl. 2, S56-S62.

30. Academy of Breastfeeding Medicine (2013) Breastfeeding support for mothers in workplace employment or educational settings: summary statement. Breastfeed Med $\mathbf{8}$, $137-142$. 